OPEN ACCESS

Edited by:

Feng Gao,

Tianjin University, China

Reviewed by:

Christopher Morton Thomas,

University of Birmingham, UK

Ramon Diaz Orejas,

Consejo Superior de Investigaciones

Científicas, Spain

*Correspondence:

Antonio Juárez

ajuarez@ub.edu

Specialty section:

This article was submitted to Evolutionary and Genomic

Microbiology,

a section of the journal

Frontiers in Microbiology

Received: 28 October 2015

Accepted: 18 April 2016

Published: 03 May 2016

Citation:

Tassinari E, AznarS, Urcolal, Prieto A, Hüttener M and Juárez A (2016) The incC Sequence Is Required for R27 Plasmid Stability.

Front. Microbiol. 7:629.

doi: 10.3389/fmicb.2016.00629

\section{The incC Sequence Is Required for R27 Plasmid Stability}

\author{
Eleonora Tassinari', Sonia Aznar ${ }^{1}$, Imanol Urcola ${ }^{1}$, Alejandro Prieto ${ }^{2}$, Mário Hüttener ${ }^{1}$ \\ and Antonio Juárez ${ }^{1,2 *}$ \\ ${ }^{1}$ Institut de Bioenginyeria de Catalunya, Barcelona, Spain, ${ }^{2}$ Departament de Microbiologia, Facultat de Biologia, Universitat \\ de Barcelona, Barcelona, Spain
}

IncHI plasmids account for multiple antimicrobial resistance in Salmonella and other enterobacterial genera. These plasmids are generally very stable in their bacterial hosts. R27 is the archetype of IncHl1 plasmids. A high percentage of the R27-encoded open reading frames (ORFs) (66.7\%) do not show similarity to any known ORFs. We performed a deletion analysis of all non-essential R27 DNA sequences to search for hitherto non-identified plasmid functions that might be required for plasmid stability. We report the identification of a short DNA sequence (incC) that is essential for $\mathrm{R} 27$ stability. That region contains several repeats (inc $C$ repeats), belongs to one of the three-plasmid replicons (R27 FIA-like) and is targeted by the R27 E protein. Deletion of the incC sequence drastically reduces R27 stability both in Escherichia coli and in Salmonella, the effect being more pronounced in this latter species. Interfering with incC-E protein interaction must lead to a reduced IncHIl plasmid stability, and may represent a new approach to combat antimicrobial resistance.

Keywords: IncHI1 plasmids, plasmid R27, plasmid stability, antimicrobial resistance, incC, E protein

\section{INTRODUCTION}

Resistance to antimicrobial compounds (AMR) is nowadays considered as a major global threat to public health (WHO, 2014). Plasmids play a key role in the dissemination of AMR, since they facilitate the spread of the resistance determinants, can be positively selected by antimicrobial compounds, and are difficult to cure or to counteract by the available strategies (Carattoli, 2013). Novel Eco-Evo strategies to combat AMR take into account that AMR is widespread in the nature and are focused to prevent the evolution and emergence of resistant bacteria in the environment (Baquero et al., 2011). The goal of these new approaches is not to kill multiresistant microorganisms, but to prevent their emergence or evolution, or to reestablish the antibiotic susceptible populations. In this context, controlling persistence and dissemination of resistance plasmids (R plasmids) is considered as a key strategy to fight AMR (Baquero et al., 2011). In the absence of selection, persistence relies on the ability of the plasmids to be stably maintained in their hosts, and in the ability of these genetic elements to be transmitted by horizontal gene transfer mechanisms. Acquisition of a plasmid may result initially in a fitness cost to the host (Dahlberg and Chao, 2003). The reasons behind plasmid biological cost remain poorly investigated. It is known that such a cost frequently peaks after the acquisition of a novel plasmid for the host organism, and the cost is progressively reduced during coexistence time, in a kind of "plasmid domestication" (Baquero et al., 2011). Domestication probably results from a complex rewiring of the cell metabolism involving the presence of the plasmid. 
Plasmid cost frequently increases upon expression of the resistance gene(s) (for instance, after transcriptional induction), and this cost is variable for different genes (Nogueira et al., 2009). Plasmid biological cost is the reason why large plasmids are always present in low copy numbers in their bacterial hosts. Otherwise, the metabolic burden of maintaining and duplicating their genomes would be excessive. Therefore, mechanisms that ensure faithfully transmission to daughter cells during cell division are required (Nordström and Austin, 1989). Mechanisms underlying plasmid stability include partitioning, multimer resolution and post-segregational killing (Sengupta and Austin, 2011). In spite of the presence of these mechanisms, some plasmids can be lost at detectable frequencies in the absence of selective pressure. On the other hand, several plasmids encoding AMR are extremely stable in their bacterial hosts. Hence, it is relevant to investigate novel mechanisms influencing plasmid stability as a means to design new strategies to combat antimicrobial resistance.

Plasmids of the incompatibility group IncHI are widespread in the Enterobacteriaceae. Within the genus Salmonella, they account for a significant proportion of antibiotic resistance in the most common invasive Salmonella serovars: S. enterica serovar Typhi and S. Paratyphi A (Holt et al., 2011). With respect to $S$. Typhi, antimicrobial resistant typhoid has been observed for half a century and is now common in many areas. IncHI plasmids are prevalent in S. Typhi: more than $40 \%$ of all isolates harbor an IncHI plasmid (Holt et al., 2011). In the last years, IncHI plasmids encoding extended-spectrum beta-lactamases (EMBLs that hydrolyze cephalosporins) and carbapenemases (the antibiotic choice to combat strains expressing EMBLs) have also been isolated in other enterobacteria such as Citrobacter or Klebsiella (Villa et al., 2012; Dolejska et al., 2013).

Regulation of conjugative transfer of IncHI plasmids shows a distinctive feature: transfer is repressed at temperatures within the host $\left(37^{\circ} \mathrm{C}\right)$ and induced at temperatures outside the host (22-30 ${ }^{\circ}$ C; Maher et al., 1993). Plasmid R27 is the prototype of IncHI plasmids. It encodes resistance to tetracycline (Tc) only and has been intensively studied for over 20 years. R27 replication and conjugation determinants are well characterized (Lawley et al., 2002; Alonso et al., 2005) and its complete nucleotide sequence is available (Sherburne et al., 2000). IncHI plasmids share a common core of about $160 \mathrm{kbp}$. The differences in size are due to the distinct presence of insertion elements (Gilmour et al., 2004). It displays two features that are shared by many $\mathrm{R}$ plasmids: (i) When present in its host (Salmonella), R27 is fairly stable, and (ii) a very significant percentage of the $\mathrm{R} 27$-encoded open reading frames (ORFs) (66.7\%) do not show similarity to any known ORFs. As a means to elaborate a strategy to reduce R27 stability in Salmonella, we decided to investigate if any of the ORFs of unknown function plays a role enhancing plasmid stability.

\section{MATERIALS AND METHODS}

\section{Bacterial Strains and Plasmids}

All bacterial strains and plasmids used in this work are listed in Table 1. Oligonucleotides for PCR amplification are listed in
TABLE 1 | Bacterial strains and plasmids used in this work.

\begin{tabular}{|c|c|c|}
\hline Strain & Relevant characteristics & Reference or source \\
\hline $\begin{array}{l}\text { Escherichia coli } \\
\text { MG1655 }\end{array}$ & F-, ilvG, rph1 & Guyer et al., 1981 \\
\hline BL21DE3 & $\begin{array}{l}\text { T7 polymerase upon } \\
\text { IPTG induction }\end{array}$ & Studier and Moffatt, 1986 \\
\hline SL1344 & $\begin{array}{l}\text { Salmonella enterica serovar } \\
\text { Typhimurium SL1344 his }\end{array}$ & Gulig and Curtiss, 1987 \\
\hline Plasmid & Description & Reference and provenience \\
\hline pKD3 & oriR $\gamma, \mathrm{Cm}^{r}$, and $\mathrm{Ap}^{r}$ & Datsenko and Wanner, 2000 \\
\hline pKD46 & $\begin{array}{l}\text { oriR101, repA101 (ts), } \\
\text { AraBp-gam-bet-exo (Red } \\
\text { helper plasmid, Ts; Apr) }\end{array}$ & Datsenko and Wanner, 2000 \\
\hline $\mathrm{R} 27$ & $\operatorname{IncHI} 1, \mathrm{TC}^{r}$ & Grindley et al., 1972 \\
\hline pLATE31 & $\begin{array}{l}\text { Bacterial expression of } \\
\text { proteins with C-terminal } 6 x \\
\text { His-tag }\end{array}$ & Thermo Scientific \\
\hline
\end{tabular}

Supplementary Table S1. Except for conjugation experiments, cultures were grown in Luria Bertani (LB) broth $\left(10 \mathrm{~g} \mathrm{l}^{-1} \mathrm{NaCl}\right.$, $10 \mathrm{~g} \mathrm{l}^{-1}$ tryptone, and $5 \mathrm{~g} \mathrm{l}^{-1}$ yeast extract) with vigorous shaking at $200 \mathrm{rpm}$ (Innova 3100, New Brunswick Scientific). SOB medium (20 $\mathrm{g} \mathrm{l}^{-1}$ Peptone, $5 \mathrm{~g} \mathrm{l}^{-1}$ yeast extract, $0.58 \mathrm{~g} \mathrm{l}^{-1} \mathrm{NaCl}$, $0.19 \mathrm{~g} \mathrm{l}^{-1} \mathrm{KCl}$, and $20 \mathrm{mM} \mathrm{MgCl}_{2}+\mathrm{MgSO}_{4}$ per liter; Hanahan et al., 1991) was used to grow bacteria for the inactivation gene experiments. SOC medium (SOB medium with $20 \mathrm{mM}$ glucose) was used to recover cells after electroporation during gene inactivation experiments. Penassay broth $\left(\mathrm{PB} ; 1.5 \mathrm{~g} \mathrm{l}^{-1}\right.$ beef extract, $1.2 \mathrm{~g} \mathrm{l}^{-1}$ yeast extract, $5 \mathrm{~g} \mathrm{l}^{-1}$ peptone, $1 \mathrm{~g} \mathrm{l}^{-1}$ glucose, $3.5 \mathrm{~g} \mathrm{l}^{-1} \mathrm{NaCl}, 1.32 \mathrm{~g} \mathrm{l}^{-1} \mathrm{KH}_{2} \mathrm{PO}_{4}$, and $4.82 \mathrm{~g} \mathrm{l}^{-1} \mathrm{KHPO}_{4} \cdot 3 \mathrm{H}_{2} \mathrm{O}$ ) was used to perform conjugal transfer. MacConkey agar was used to distinguish $S$. enterica serovar Typhimurium from Escherichia coli cells upon conjugation.

When necessary, the media were supplemented with $10 \mathrm{mM}$ L-arabinose or with the following antibiotics: ampicillin $(100 \mu \mathrm{g}$ $\left.\mathrm{ml}^{-1}\right)$, chloramphenicol $\left(25 \mu \mathrm{g} \mathrm{ml}^{-1}\right)$, or Tc $\left(15 \mu \mathrm{g} \mathrm{ml}^{-1}\right)$.

\section{Genetic Manipulations}

All enzymes used to perform standard molecular and genetic procedures were used according to the manufacturer's recommendations. To introduce plasmids in E. coli, bacterial cells were grown until a $\mathrm{OD}_{600} \mathrm{~nm}$ 0.6-0.8. Then, cells were washed several times with $10 \%$ glycerol, and the respective plasmids and PCR-amplified DNA fragments were introduced by electroporation $(1,250 \mathrm{~V})$ using an Eppendorf gene pulser (Electroporator 2510).

R27 mutant derivatives lacking different DNA fragments in strain E. coli MG1655 were obtained by the $\lambda$ Red recombinase method as described (Datsenko and Wanner, 2000). Briefly, the antibiotic-resistance cassette of chloramphenicol of plasmid pKD3 was amplified by PCR using pairs of about 56-70 ntlong primers, of which 36-50 nt are homologous to the up and downstream regions of the R27 sequences to be disrupted, while the remaining sequences pair up with the P1 or P2 sites on pKD3 plasmid. DNA templates were treated with DpnI (Thermo Scientific) following manufacturer recommendations, 
and then, purified and electroporated to the competent E. coli cells harboring plasmids pKD46 and R27. Mutants were selected on LB plates containing the appropriate selection marker (chloramphenicol in this case) and the successful deletion of the desired R27 fragment was confirmed by PCR.

\section{Plasmid Stability Assay}

Plasmid stability has been determined upon seven successive subcultures at a ratio of 1:10.000 of the plasmid-carrier strain on LB medium (unless otherwise indicated, at $37^{\circ} \mathrm{C}$ ) without antibiotic. After the first and the last overnight cultures, aliquots were diluted and spread on LB agar plates. The isolated colonies were picked in duplicate to LB agar plates with and without antibiotic. Tc-sensitive clones were confirmed for plasmid loss and not for Tn10 loss by PCR. Oligonucleotides Del2_up and Del2_Inner (see Supplementary Table S1) amplify a 524 bp region of R27. These oligonucleotides do not amplify chromosomal DNA. Plasmid stability is expressed as the percentage of colonies, which maintain the plasmid, and it is determined as the ratio between the number of antibioticresistant isolates and the total number of colonies replicated on LB medium lacking the antibiotic.

\section{Bioinformatic Analysis}

To search for similarities of the $322 \mathrm{bp}$ sequence included in deletion DelNCD, the blastN algorithm was used (Altschul et al., 1990). The results were filtered and only hits with an identity of higher than $95 \%$ and coverage of higher than $90 \%$ were considered as positive.

\section{E Protein Purification}

The recombinant plasmid for C-terminal His-tagged R27encoded $\mathrm{E}$ protein overexpression was obtained following the instructions of ALICator Ligation Independent Cloning and Expression System (Thermo Scientific) using primers RepECtermFor and RepECtermRev (Supplementary Table S1). Recombinant clones were sequenced before overexpression.

Transformed BL21(DE3) cells were grown at $37^{\circ} \mathrm{C}$ in $\mathrm{LB}$ until the cultures reached an $\mathrm{OD}_{600 \mathrm{~nm}}$ of $0.5-0.6$. Isopropyl- $\beta-\mathrm{D}-1$ thiogalactopyranoside (IPTG) was subsequently added to a final concentration of $1 \mathrm{mM}$. Upon $3 \mathrm{~h}$ incubation at $37^{\circ} \mathrm{C}$, cells were centrifuged and pellets were frozen, resuspended in lysis buffer (50 $\mathrm{mM} \mathrm{NaH}_{2} \mathrm{PO}_{4} \mathrm{pH} \mathrm{8,1} \mathrm{M} \mathrm{KCl,} 10 \mathrm{mM}$ imidazole suplemented with $1 \mathrm{mg} \mathrm{ml}^{-1}$ ) of lysozyme and a protease inhibitor cocktail (cOmplete ULTRA Tablets Mini, EDTA-free, EASYpack Roche) and disrupted by sonication on ice. The lysate was centrifuged at $20,000 \times g$ for $30 \mathrm{~min}$ at $4^{\circ} \mathrm{C}$, and the supernatant was then treated with Ni-NTA $\left(\mathrm{Ni}^{2+}\right.$-nitrilotriacetate)-agarose (Qiagen). The resin was washed extensively with the same buffer, and the protein was eluted using $200 \mathrm{mM}$ imidazole as described previously (Nieto et al., 2000).

\section{Band Shift Assays}

Band shift assay were performed in the presence of radiolabeled incC DNA together with increasing concentrations of $\mathrm{E}$ protein-his. A $235 \mathrm{nt}$ fragment corresponding to the R27 incC sequence (nucleotide positions 156,644-156,878 - NCBI accession number NC_002305.1) was generated by PCR using primers incCFor/incCRev (Supplementary Table S1) and gelpurified. Ten picomoles of the PCR product was radiolabeled with $[\gamma-32 \mathrm{P}]$ ATP (PerkinElmer) using T4 Polynucleotide Kinase (ThermoScientific) according to the manufacturer's instructions. For each reaction, 20 fmol DNA template was mixed with $200 \mathrm{ng}$ of poly $(\mathrm{dI}-\mathrm{dC})$ and increasing concentrations of $\mathrm{E}$ protein-his (0.24-3.84 $\mu \mathrm{M})$ in binding buffer (250 mM 4-(2-hydroxyethyl)1-piperazineethanesulfonic acid (HEPES), pH 7.4, $350 \mathrm{mM} \mathrm{KCl}$, $5 \mathrm{mM}$ EDTA, $5 \mathrm{mM}$ dithiothreitol (DTT), $500 \mu \mathrm{g}$ BSA ml -1 , and $25 \%, v / v$, glycerol) and incubated at room temperature for $30 \mathrm{~min}$. The samples $(20 \mu \mathrm{l})$ were separated on a $5 \%$ polyacrylamide/0.5× Tris-Borate-EDTA (TBE) gel. The bands were visualized using Quantity One software (Bio-Rad).

\section{RESULTS}

\section{Construction of R27 Plasmid Deletions}

Deletions in plasmid R27 were performed in the host strain E. coli MG1655. Deletion length was about 5-7 kbp. Deletions covered the complete sequence of plasmid R27, leaving out the two main replicons, the regions involved in plasmid stability/partitioning and in plasmid conjugation and the Tc resistance determinant (Tn10). The overall number of deletions attempted is 19. Every deletion includes several ORFs whose function in many instances is unknown, and only their similarity percentage with proteins of known function has been annotated. Plasmid location, precise length, and the genes included in each deletion are listed in Supplementary Table S2. Figure 1 summarizes the deletions performed in the R27 sequence.

Upon screening, several positive colonies were obtained for each deletion except for deletion 18 which, was unsuccessfully attempted several times. A single colony containing each of the different R27 derivatives (deletions 1-17 and 19), was purified, checked by PCR, and used to study plasmid stability. Only R27 derivative harboring deletion 16 showed a very significant

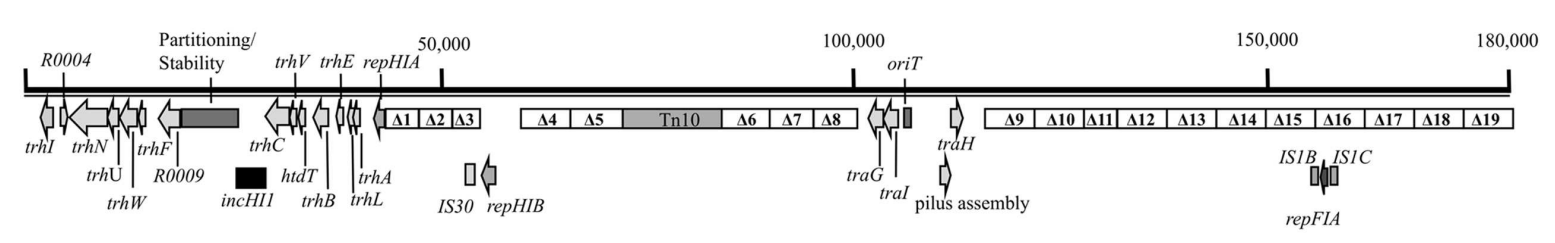

FIGURE 1 | R27 physical map. The 19 deletions attempted are shown $(\Delta 1-\Delta 19)$. 
decrease of stability (85\%). We therefore decided to identify the DNA sequences included in the DNA fragment deleted in plasmid $\mathrm{R} 27 \Delta 16$ that play a role in R27 stability in strain MG1655.

\section{incC Repeats Are Required for R27 Plasmid Stability in E. coli Strain MG1655}

To identify the DNA sequences whose deletion reduces R27 plasmid stability, a fine mapping analysis was performed. The 6.5-kb DNA fragment replaced in deletion 16 (Figure 2) includes eight ORFs, some of which share an extended homology with known proteins, as in the case of ORFs R0179, R0180, R0181, and R0182. The rest do not show significant similarity to other identified ORFs (see Supplementary Table S2). We initially hypothesized that any of the single ORFs encoded in the deleted DNA fragment should account for plasmid loss. To confirm this, single ORF deletion mutant derivatives of plasmid R27 were constructed in strain MG1655 using the same mutagenesis protocol previously described. The single deletions were designed at the exact ends of the corresponding ORFs (Supplementary Table S2; Figure 2A). Plasmid stability assays were performed with the eight R27 derivatives lacking each of the eight ORFs included in the DNA fragment. No single deletion accounted for the previously observed reduced R27 stability (data not shown). We hypothesized then that plasmid instability of R27 $\Delta 16$ variant being caused by a combined effect of more than one of the corresponding ORFs. To confirm this, we performed deletions combining different ORFs (see Supplementary Table S2; Figure 2B). The resulting R27 derivatives were tested for plasmid stability. Again, no effect was observed (data not shown).
The unique DNA fragment not included in the combined deletions of fragment R27-16 is a 348-bp sequence located in its $5^{\prime}$ end (Figure 2). This non-coding DNA region includes a 25-nt-long fragment of IS1b $3^{\prime}$-end (an insertion sequence) while the remainder of the sequence is not annotated on the previously published R27 map (Sherburne et al., 2000). As this sequence had hitherto not been included in the partial deletions constructed within the DNA fragment corresponding to deletion 16 , we performed a new deletion in plasmid R27, spanning from the exact beginning of the DNA sequence corresponding to deletion 16 end, to ORF R0182 (hha) included (Figure 2). The new plasmid derivative, R27 $\Delta 16 \mathrm{P} 1-182$, exhibited high plasmid instability (23\% plasmid loss). As this latter large deletion included the 348 nucleotides upstream ORF R0179 and confers plasmid instability, we hypothesized that deletion of the 348-bp DNA fragment, either alone or in combination with any ORF included in deletion 16P1-182 accounts for the observed plasmid instability. To clarify this, a new deletion in R27 was obtained spanning from nucleotides 156,500156,890 (Figure 2). The mutant plasmid obtained (R27 $\Delta \mathrm{NCD}$ ) was then analyzed for plasmid stability. Plasmid loss was of $38 \%$.

Upon having confirmed that deletion of a short non-coding region comprised between R27 nucleotides 156,500 and 156,890 significantly reduces R27 stability, the sequence was blasted to search for similarities with already characterized DNA sequences. We used for the analysis the 322-bp sequence within deletion DelNCD which is not annotated on R27 map (Sherburne et al., 2000). The results obtained (Supplementary Table S3) show that the sequence aligns completely and for its whole length with sequences present in several other plasmids, mainly isolated from the Enterobacteriaceae. Remarkably, that sequence is present in
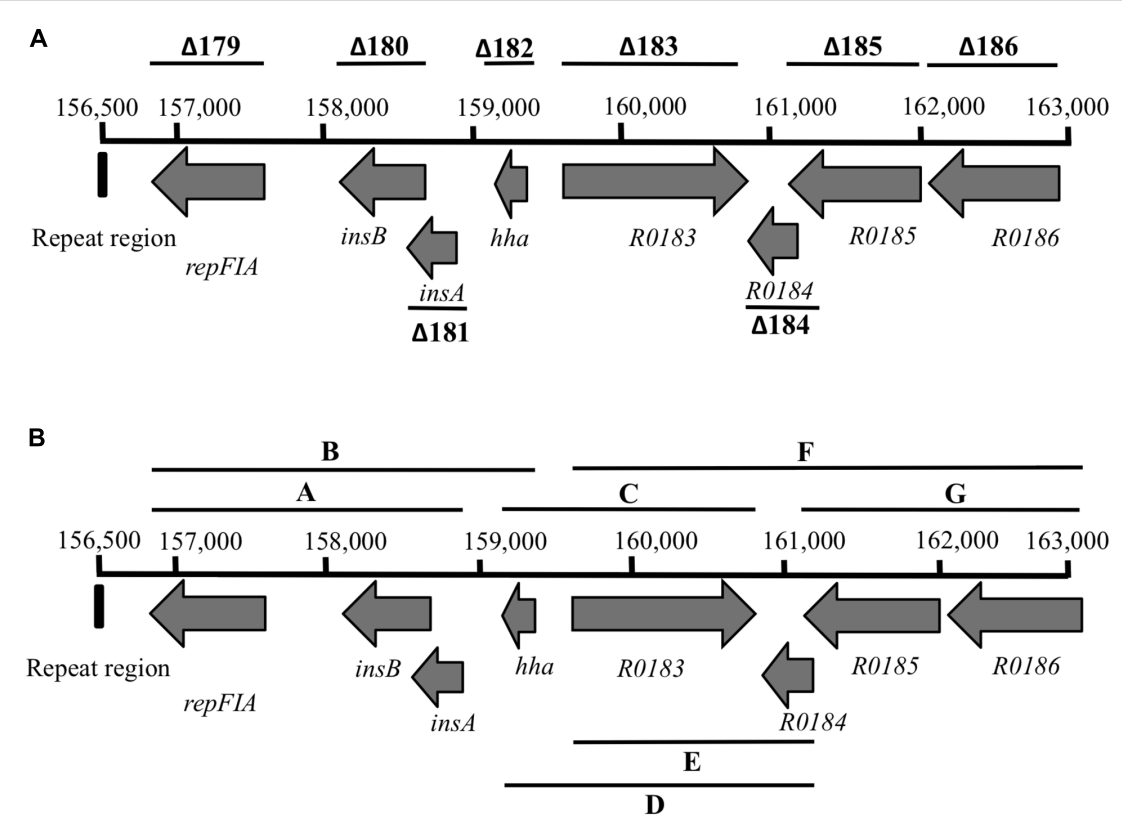

FIGURE 2 | Physical map of the 6.5-kb DNA fragment replaced in deletion 16. (A) Deletions performed affecting each of the ORFs included in the fragment. (B) Combined deletions in the 6.5-kb DNA fragment. 


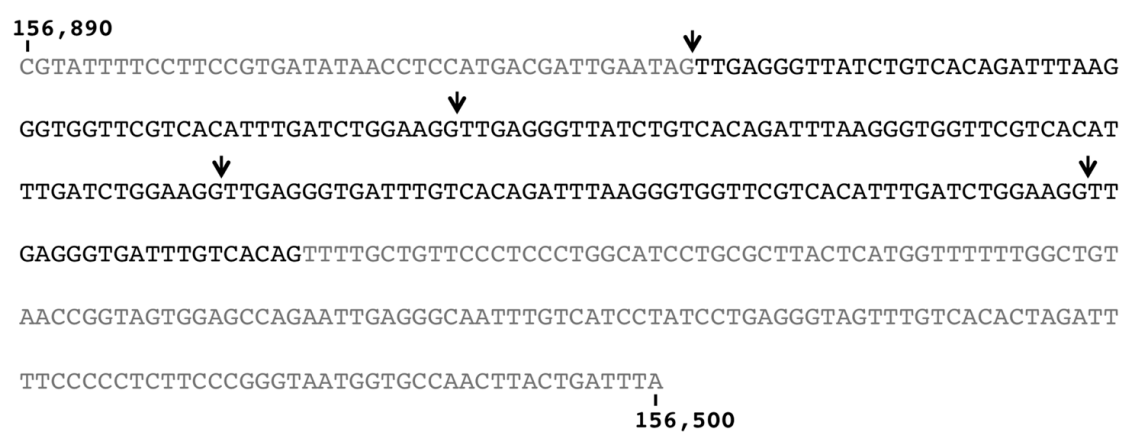

FIGURE 3 | inc $\mathbf{C}$ region. Arrows point to the start and end of the different inc $C$ repeats. Note that the last inc $C$ repeat is truncated.

\section{A}

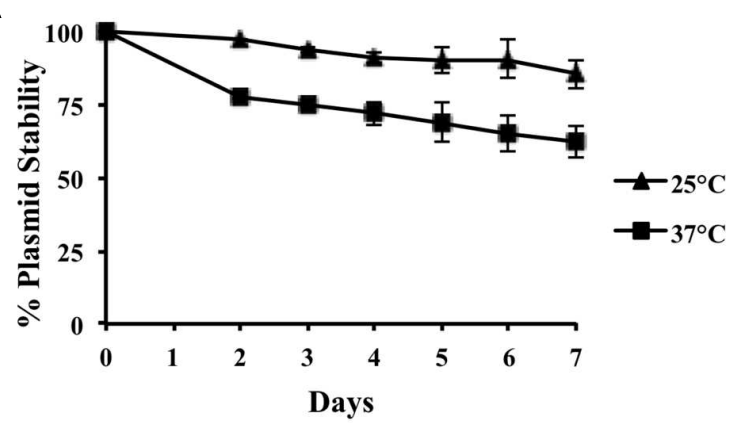

B

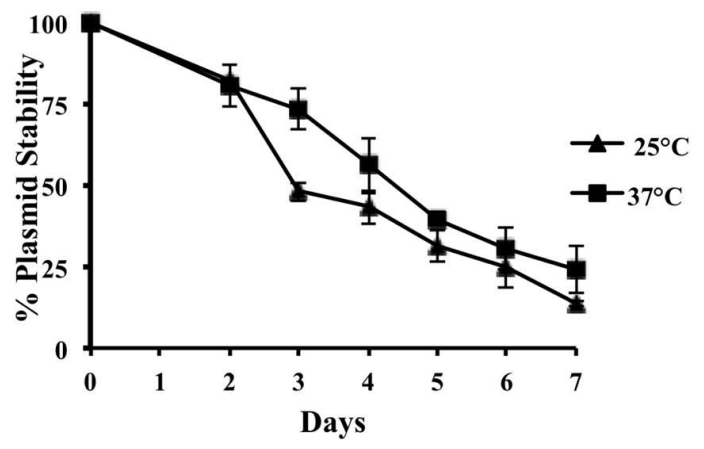

FIGURE 4 | Stability of R27 $\triangle$ NCD in E. coli MG1655 (A) and S. Typhimurium SL1344 (B) growing at 25 and $37^{\circ} \mathrm{C}$, respectively. The stability of wt R27 in these strains at both temperatures is of $100 \%$ upon seven subcultures.

IncHI as well as in IncF plasmids. It belongs to the IncFIA-like replicon of R27 (Saul et al., 1988), and corresponds to incC (Figure 3). It has been shown that that this sequence includes directed repeats that are targeted by the E protein (Saul et al., 1988).

\section{The incC Sequence Is Required for High Stability of R27 Plasmid in E. coli and Salmonella}

We decided next to more precisely determine the role of the incC sequence in plasmid stability both in E. coli and Salmonella. For plasmid stability studies in E. coli, strain MG1655 was used. We compared plasmid stability at 25 and $37^{\circ} \mathrm{C}$ along 100 generations. MG1655 cells harboring wt R27 do not lose the plasmid at a detectable frequency. When hosted in strain MG1655, R27 incC sequence plays a relevant role in plasmid stability when cells grow at $37^{\circ} \mathrm{C}$, but not when cells grow at $25^{\circ} \mathrm{C}$ (Figure $4 \mathbf{A}$ ). Taking into account that IncHI plasmids are predominantly isolated from Salmonella strains, we decided to test the role of incC in this microorganism. Plasmid R27 $\triangle$ NCD was conjugated to $S$. Typhimurium strain SL1344 and transconjugants were then used to analyze plasmid stability both at 37 and $25^{\circ} \mathrm{C}$ (Figure $4 \mathbf{B}$ ). Remarkably, both at 37 and $25^{\circ} \mathrm{C}$, the role of incC on plasmid stability is even more relevant in strain SL1344 than in strain MG1655. In strain SL1344, R27 $\triangle$ NCD plasmid loss occurs at higher frequencies; being this case, the effect of temperature is negligible.

\section{R27-Encoded E protein Binds the inc C Sequence}

It was indirectly shown that R27 inc $C$ sequences were able to bind F plasmid-encoded E protein (Saul et al., 1988), but no direct evidence of R27 E protein binding inc C sequences has hitherto been provided. To show this, we purified his-tagged R27 E protein and performed band shift assays with a 235-bp DNA fragment including the inc $C$ sequences. As predicted, low mobility proteinDNA complexes are obtained upon incubating E protein with the DNA fragment (Figure 5).

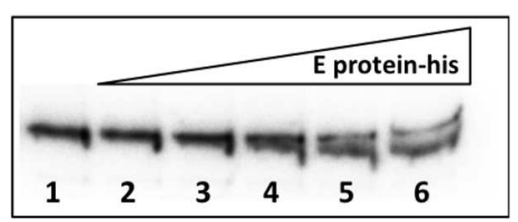

FIGURE 5 | Band shift assay of the R27 E protein with a DNA fragment including the inc $\boldsymbol{C}$ sequences. Reactions were performed in presence of incC DNA, $20 \mathrm{fmol}$, together with $200 \mathrm{ng}$ of Poly(dl-dC) for each reaction, and increasing concentration of E protein-his. Lane 1, No protein; lane 2, $0.24 \mu \mathrm{M}$; lane 3, $0.48 \mu \mathrm{M}$; lane 4, $0.96 \mu \mathrm{M}$; lane 5, $1.92 \mu \mathrm{M}$; and lane 6, 3.84 $\mu \mathrm{M}$. 


\section{DISCUSSION}

IncHI1 plasmids such as R27 contain three replicons (RepHI1A, RepHI1B, and RepFIA-like). Previous studies showed that deletion of the RepFIA sequences from R27 leaves a plasmid, which is both compatible with $\mathrm{F}$ and replication-proficient. Each of both RepHI1 replicons appears to be capable of taking over the replication of the plasmid (Gabant et al., 1993). The deletion analysis we performed in plasmid R27 allowed us to identify sequences that map within R27 RepFIA sequences and are required for R27 plasmid stability. Remarkably, the R27 incC region whose deletion leads to a marked plasmid instability corresponds to the less conserved region of the RepFIA replicon in R27. When compared to the corresponding region in $\mathrm{F}$ plasmid, inc $\mathrm{C}$ repeats are conserved, but not the spacer regions (Saul et al., 1988). R27 RepFIA region was shown to contain a functional $\mathrm{E}$ protein, able to repress the $\mathrm{E}$ promoter and to initiate replication from $\mathrm{F}$ ori2. R27 incB and inc $C$ sequences were also shown to bind $\mathrm{F}$ plasmid-encoded E protein. RepFIA region of plasmid R27 was considered as responsible for the incompatibility of R27 and F plasmids (Saul et al., 1988). Although all three IncHI1 replicons were identified several years ago (Saul et al., 1988; Gabant et al., 1993, 1994; Newnham and Taylor, 1994) the reasons for the simultaneous presence of all three replicons in this plasmid Inc group remain to be elucidated, as well as their specific biological role. It has been suggested that the carriage of multiple, independent replicons allow plasmids to coexist with other competing plasmids within the same bacterial cell (Gabant et al., 1993).

The results reported here add new information about the biological role of sequences belonging to the RepFIA replicon of R27. Although it has been reported that the either RepHI1A and RepHI1B replicon can overtake R27 replication (Gabant et al., 1993), the results we obtained show that the incC region itself plays a critical role in R27 stability, both in E. coli and in Salmonella. In the absence of incC, replication initiation from the two other alternative replicons appears to be less efficient. If one assumes that the observed effect of incC sequences on plasmid stability is due to protein E-incC interaction, different hypotheses can explain this. In the wt system, protein E-DNA interaction could either titrate the replication initiation protein, hence reducing the replication potential, or promote plasmid replication. Hence, interference with protein E-DNA interaction can either increase plasmid copy number and plasmid stability, or interfere with plasmid replication and reduce plasmid stability. As well, a hypothesis to explain the observed effect is that excess of free-E protein might result in handcuffing interactions between Rep proteins bound at ori sequences.

The effect of R27 incC deletion is host-dependent: whereas incC deletion has a moderate effect on R27 stability in E. coli, deletion of these repeats has a very relevant effect on R27 stability in Salmonella. Growth temperature also appears to influence R27 stability in plasmid derivatives lacking incC sequences in E. coli: reduced plasmid stability can be significantly observed at $37^{\circ} \mathrm{C}$, but it is almost neglectable at $25^{\circ} \mathrm{C}$. The effect of growth temperature is not significant in Salmonella. In this host, stability of R27 $\triangle \mathrm{NCD}$ is much lower than that of the wt plasmid both at 37 and at $25^{\circ} \mathrm{C}$. These results suggest that carriage of multiple independent replicons not only may allow plasmids to coexist with other plasmids, but to efficiently replicate in different bacterial hosts and under different environmental conditions.

IncHI1 plasmids can be found both in natural E. coli and Salmonella isolates. Nevertheless, whereas their presence is scarce in the former (Johnson et al., 2007, 2008), they can be frequently isolated in the latter (Holt et al., 2011). As commented above, they play a relevant role in the AMR phenotype of the Salmonellae. IncHI plasmids are conjugatively transferred at temperatures of about $25^{\circ} \mathrm{C}$ (Maher et al., 1993) and, when Salmonella cells grow at these temperatures, a sophisticated crosstalk between these plasmids and the host regulatory networks is established. As a result, IncHI plasmids increase the fitness of Salmonella cells (Paytubi et al., 2013). Remarkably, under these conditions, the incC region plays a critical role in ensuring IncHI plasmids stability.

Although the basis for the pronounced instability of R27 in the absence of $i n c C$ repeats remains to be elucidated, the fact that these sequences are critical for plasmid maintenance in Salmonella raises the possibility of targeting them with the aim to reduce IncHIl plasmid stability in this microorganism and hence, develop a new approach to decontaminate antibiotic resistance. The fact that at least in vitro the $\mathrm{R} 27 \mathrm{E}$ protein is able to bind $\mathrm{R} 27$ inc C sequences suggests that molecules able to interfere with this interaction might be candidates to be tested to reduce IncHI plasmids stability.

\section{AUTHOR CONTRIBUTIONS}

Conceived and designed the experiments: ET, SA, and AJ. Performed the experiments: ET, IU, and AP. Analyzed the data: ET, SA, MH, and AJ. Wrote the manuscript: ET, SA, MH, and AJ. All authors read and approved the final manuscript.

\section{ACKNOWLEDGMENT}

The authors acknowledge funding from the Spanish MICINNFEDER (CSD2008-00013), Mineco (BIO2013-49148-C2-1-R) and (BIO2015-69085-REDC).

\section{SUPPLEMENTARY MATERIAL}

The Supplementary Material for this article can be found online at: http://journal.frontiersin.org/article/10.3389/fmicb.2016. 00629

TABLE S1 | Oligonucleotide sequences used in this work.

TABLE S2 | R27 sequences included in the different deletions.

TABLE S3 | Results of the BlastN analysis. 


\section{REFERENCES}

Alonso, G., Baptista, K., Ngo, T., and Taylor, D. E. (2005). Transcriptional organization of the temperature-sensitive transfer system from the IncHI1 plasmid R27. Microbiology 151, 3563-3573. doi: 10.1099/mic.0.28256-0

Altschul, S. F., Gish, W., Miller, W., Myers, E. W., and Lipman, D. J. (1990). Basic local alignment search tool. J. Mol. Biol. 215, 403-410. doi: 10.1016/S00222836(05)80360-2

Baquero, F., Coque, T. M., and la Cruz de, F. (2011). Ecology and evolution as targets: the need for novel eco-evo drugs and strategies to fight antibiotic resistance. Antimicrob. Agents Chemother. 55, 3649-3660. doi: 10.1128/AAC.00013-11

Carattoli, A. (2013). Plasmids and the spread of resistance. Int. J. Med. Microbiol. 303, 298-304. doi: 10.1016/j.ijmm.2013.02.001

Dahlberg, C., and Chao, L. (2003). Amelioration of the cost of conjugative plasmid carriage in Eschericha coli K12. Genetics 165, 1641-1649.

Datsenko, K. A., and Wanner, B. L. (2000). One-step inactivation of chromosomal genes in Escherichia coli K-12 using PCR products. Proc. Natl. Acad. Sci. U.S.A. 97, 6640-6645. doi: 10.1073/pnas.120163297

Dolejska, M., Villa, L., Poirel, L., Nordmann, P., and Carattoli, A. (2013). Complete sequencing of an IncHI1 plasmid encoding the carbapenemase NDM-1, the ArmA 16S RNA methylase and a resistance-nodulation-cell division/multidrug efflux pump. J. Antimicrob. Chemother. 68, 34-39. doi: 10.1093/jac/dks357

Gabant, P., Chahdi, A. O., and Couturier, M. (1994). Nucleotide sequence and replication characteristics of RepHI1B: a replicon specific to the IncHI1 plasmids. Plasmid 31, 111-120. doi: 10.1006/plas.1994.1012

Gabant, P., Newnham, P., Taylor, D., and Couturier, M. (1993). Isolation and location on the R27 map of two replicons and an incompatibility determinant specific for IncHI1 plasmids. J. Bacteriol. 175, 7697-7701.

Gilmour, M. W., Thomson, N. R., Sanders, M., Parkhill, J., and Taylor, D. E. (2004). The complete nucleotide sequence of the resistance plasmid R478: defining the backbone components of incompatibility group $\mathrm{H}$ conjugative plasmids through comparative genomics. Plasmid 52, 182-202. doi: 10.1016/j.plasmid.2004.06.006

Grindley, N., Grindley, J. N., and Anderson, E. S. (1972). R factor compatibility groups. Mol. General 119, 287-297. doi: 10.1007/BF00272087

Gulig, P. A., and Curtiss, R. (1987). Plasmid-associated virulence of Salmonella typhimurium. Infect. Immun. 55, 2891-2901.

Guyer, M. S., Reed, R. R., Steitz, J. A., and Low, K. B. (1981). Identification of a sexfactor-affinity site in E. coli as gamma delta. Cold Spring Harb. Symp. Quant. Biol. 45(Pt 1), 135-140. doi: 10.1101/SQB.1981.045.01.022

Hanahan, D., Jessee, J., and Bloom, F. R. (1991). Plasmid transformation of Escherichia coli and other bacteria. Methods Enzymol. 204, 63-113. doi: 10.1016/0076-6879(91)04006-A

Holt, K. E., Phan, M. D., Baker, S., Duy, P. T., Nga, T. V. T., Nair, S., et al (2011). Emergence of a globally dominant IncHIl plasmid type associated with multiple drug resistant typhoid. PLoS Negl. Trop Dis. 5:e1245. doi: 10.1371/journal.pntd.0001245

Johnson, T. J., Wannemuehler, Y. M., Johnson, S. J., Logue, C. M., White, D. G., Doetkott, C., et al. (2007). Plasmid replicon typing of commensal and pathogenic Escherichia coli isolates. Appl. Environ. Microbiol. 73, 1976-1983. doi: 10.1128/AEM.00760-07

Johnson, T. J., Wannemuehler, Y., Johnson, S. J., Stell, A. L., Doetkott, C., Johnson, J. R., et al. (2008). Comparison of extraintestinal pathogenic Escherichia coli strains from human and avian sources reveals a mixed subset representing potential zoonotic pathogens. Appl. Environ. Microbiol. 74, 7043-7050. doi: 10.1128/AEM.01395-08
Lawley, T. D., Gilmour, M. W., Gunton, J. E., Standeven, L. J., and Taylor, D. E. (2002). Functional and mutational analysis of conjugative transfer region 1 (Tra1) from the IncHI1 plasmid R27. J. Bacteriol. 184, 2173-2180. doi: 10.1128/JB.184.8.2173-2180.2002

Maher, D., Sherburne, R., and Taylor, D. E. (1993). H-pilus assembly kinetics determined by electron microscopy. J. Bacteriol. 175, 2175-2183.

Newnham, P. J., and Taylor, D. E. (1994). Molecular analysis of RepHI1A, a minimal replicon of the IncHI1 plasmid R27. Mol. Microbiol. 11, 757-768. doi: 10.1111/j.1365-2958.1994.tb00353.x

Nieto, J. M., Madrid, C., Prenafeta, A., Miquelay, E., Balsalobre, C., Carrascal, M., et al. (2000). Expression of the hemolysin operon in Escherichia coli is modulated by a nucleoid-protein complex that includes the proteins Hha and H-NS. Mol. Gen. Genet. 263, 349-358. doi: 10.1007/s0043800 51178

Nogueira, T., Rankin, D. J., Touchon, M., Taddei, F., Brown, S. P., and Rocha, E. P. C. (2009). Horizontal gene transfer of the secretome drives the evolution of bacterial cooperation and virulence. Curr. Biol. 19, 1683-1691. doi: 10.1016/j.cub.2009.08.056

Nordström, K., and Austin, S. J. (1989). Mechanisms that contribute to the stable segregation of plasmids. Annu. Rev. Genet. 23, 37-69. doi: 10.1146/annurev.ge.23.120189.000345

Paytubi, S., Aznar, S., Madrid, C., Balsalobre, C., Dillon, S. C., Dorman, C. J., et al. (2013). A novel role for antibiotic resistance plasmids in facilitating Salmonella adaptation to non-host environments. Environ. Microbiol. 16, 950-962. doi: 10.1111/1462-2920.12244

Saul, D., Lane, D., and Bergquist, P. L. (1988). A replication region of the IncHI plasmid, R27, is highly homologous with the RepFIA replicon of F. Mol. Microbiol. 2, 219-225. doi: 10.1111/j.1365-2958.1988. tb00023.x

Sengupta, M., and Austin, S. (2011). Prevalence and significance of plasmid maintenance functions in the virulence plasmids of pathogenic bacteria. Infect. Immun. 79, 2502-2509. doi: 10.1128/IAI.00127-11

Sherburne, C. K., Lawley, T. D., Gilmour, M. W., Blattner, F. R., Burland, V., Grotbeck, E., et al. (2000). The complete DNA sequence and analysis of R27, a large IncHI plasmid from Salmonella typhi that is temperature sensitive for transfer. Nucleic Acids Res. 28, 2177-2186. doi: 10.1093/nar/28.10.2177

Studier, F. W., and Moffatt, B. A. (1986). Use of bacteriophage T7 RNA polymerase to direct selective high-level expression of cloned genes. J. Mol. Biol. 189, 113-130. doi: 10.1016/0022-2836(86)90385-2

Villa, L., Poirel, L., Nordmann, P., Carta, C., and Carattoli, A. (2012). Complete sequencing of an IncH plasmid carrying the blaNDM-1, blaCTX-M-15 and qnrB1 genes. J. Antimicrob. Chemother. 67, 1645-1650. doi: 10.1093/jac/dks114 WHO (2014). Antimicrobial Resistance: Global Report on Surveillance 2014 Geneva: World Health Organization. Available at: http://www.who.int/drugre sistance/documents/surveillancereport/en

Conflict of Interest Statement: The authors declare that the research was conducted in the absence of any commercial or financial relationships that could be construed as a potential conflict of interest.

Copyright (c) 2016 Tassinari, Aznar, Urcola, Prieto, Hüttener and Juárez. This is an open-access article distributed under the terms of the Creative Commons Attribution License (CC BY). The use, distribution or reproduction in other forums is permitted, provided the original author(s) or licensor are credited and that the original publication in this journal is cited, in accordance with accepted academic practice. No use, distribution or reproduction is permitted which does not comply with these terms. 